\title{
Hybrid Tea-roses under controlled light conditions. 4. Combining ability analysis of variance for percentage of flowering in F1 populations
}

\author{
D. P. de Vries, L. Smeets and Lidwien A. M. Dubois
}

Institute for Horticultural Plant Breeding, P.O. Box 16, 6700 AA Wageningen, the Netherlands

Accepted: 6 December 1979

Key words: Rosa, Rose, Hybrid Tea, diallel, F1 population, low irradiance, flowering ability, combining ability, breeding.

\section{Summary}

F1 populations of the Hybrid Tea-roses 'Sonia', 'Baccara', 'Ilona', 'Prominent' and 'Zorina' were grown in a growth room under $8 \mathrm{~W} \mathrm{m-2}, 20^{\circ} \mathrm{C}, 8 \mathrm{~h}$. Inheritance of flowering ability under low irradiance was mainly controlled by additive gene action. 'Prominent' and 'Zorina' had a good general combining ability for flowering under low irradiance.

\section{Introduction}

Under poor (winter) light conditions cut roses grown in greenhouses produce a percentage of blind shoots, dependent on the variety (De Vries, 1977). In blind shoots the initially present flower bud has aborted.

When grown under low irradiances in a growth room, in seedling populations of Hybrid Tea (HT)-roses flowering or blind plants occurred, the ratio of which depended on the progenitors.

Because clones from seedlings that flowered under low irradiances, produce a much more favourable ratio of flowering to blind shoots than aborted ones, flowering seedlings constitute the basis of selection for winter varieties of glasshouse roses (De Vries et al., 1978). For breeding purposes it would therefore be advantageous to hybridize genotypes that transmit a high percentage of flowering under low light conditions.

In the present study the genetic variation of the flowering ability under low irradiance in $\mathrm{F} 1$ populations of HT-roses was analysed. 


\section{Material and methods}

In 1976 and 1977, 5 Hybrid Tea (HT) rose varieties - 'Sonia', 'Zorina', 'Ilona', 'Prominent' and 'Baccara' - known to differ for their ability to flower in greenhouses in winter, were crossed according to a complete diallel. After stratification and subsequent germination of the seeds in the following spring, the seedlings of each population were grown in a growth room of our phytotron under the conditions recommended by de Vries \& Smeets (1978) for the selection of winter varieties, i.e. a temperature of $20^{\circ} \mathrm{C}$, an irradiance of $8 \mathrm{~W} \mathrm{m-2}$ and a day length of $8 \mathrm{~h}$. The plants were grown till flower bud appearance or flower bud abortion could be assessed.

In 1977 one, in 1978 two experiments were carried out under identical environmental conditions. In principle 30 seedlings of each population were used in each experiment, but owing to low germination or high mortality this number was lower in 3 populations. These populations were excluded from analysis (see Table 1). In statistical analysis the 3 experiments were considered as replicates. First it was investigated whether differences in flowering percentage were significant; subsequently the genetic variance in flowering percentage was analysed according to one of the fixed models of the general technique described by Keuls \& Garretsen (1977) and Garretsen \& Keuls (1978), which relates to the concepts of general and specific combining ability (GCA and SCA, respectively).

\section{Results}

Table 1 shows that the populations differed considerably for their mean percentage of flowering plants. In Table 2 it can be seen that a very significant GCA mean square for the percentage of flowering was found. The table also shows that mean squares (MS) for SCA and reciprocals were significant. The former was caused by 'Ilona' $\times$ 'Baccara' $(3 \times 5)$ giving about $8 \%$ more flowering plants than could be expected on the basis of their GCA estimate; the latter was caused by the combination' of 'Baccara' and 'Zorina' $(5 \times 2)$.

From the relatively high MS for GCA and the low MS for SCA estimates it is evident that flowering ability (under an irradiance of $8 \mathrm{~W} \mathrm{m-2}$ ) was mainly controlled by additive gene action. In Table 3 the estimated GCAs of the 5

Table 1. Mean percentages of flowering plants in 22 HT-rose seedling populations, grown under $8 \mathrm{~W} \mathrm{~m}-^{2}(8 \mathrm{~h}), 20^{\circ} \mathrm{C}$.

\begin{tabular}{|c|c|c|c|c|c|}
\hline$q / 3$ & 1 & 2 & 3 & 4 & 5 \\
\hline 1 Sonia & 22 & 28 & 25 & 26 & 17 \\
\hline 2 Zorina & - & 62 & 43 & 51 & 23 \\
\hline 3 Ilona & 12 & 40 & 14 & 37 & 27 \\
\hline 4 Prominent & - & 58 & 33 & 52 & 36 \\
\hline 5 Baccara & 18 & 40 & 33 & - & 21 \\
\hline
\end{tabular}

Neth. J. agric. Sci. $28(1980)$ 
Table 2. Combining ability analyses of variance of the percentage of flowering of HT-rose seedlings, when grown at $8 \mathrm{~W} \mathrm{~m}^{-2}(8 \mathrm{~h}), 20^{\circ} \mathrm{C}$.

\begin{tabular}{lcc}
\hline Source & Dimension & Mean square \\
GCA & 4 & $850.6^{* *}$ \\
SCA & 10 & $50.5^{*}$ \\
Reciprocals & 7 & $40.9^{*}$ \\
Error & 32 & 17.5 \\
\hline
\end{tabular}

* $\mathrm{P}<0.05 ;{ }^{*} \mathrm{P}<0.01$.

Table 3. GCAs for 5 HT-rose varieties for the percentage of flowering under $8 \mathrm{~W} \mathrm{~m}-{ }^{2}$ $(8 \mathrm{~h}), 20^{\circ} \mathrm{C}$.

\begin{tabular}{lr}
\hline Parents & $\mathrm{GCA}$ \\
Sonia & $-9.2^{* *}$ \\
Baccara & $-5.6^{* *}$ \\
Ilona & $-4.9^{* *}$ \\
Prominent & $8.3^{* *}$ \\
Zorina & $11.5^{* *}$ \\
Overall mean & 32.7 \\
SE (GCA) & $1.2-1.3$ \\
\hline
\end{tabular}

** Very significantly different from zero.

parents are arranged in order of increasing flowering percentage. Each GCA was tested against its standard error (SE) for positive or negative deviation from zero. It appeared that 'Zorina' and 'Prominent' were progenitors with a very significant positive effect on the percentage of flowering while 'Ilona', 'Baccara' and 'Sonia' affected the flowering percentage negatively.

\section{Discussion and conclusions}

Our present experiments showed that flowering ability of Hybrid Tea-roses under low irradiance is mainly controlled by additive gene action. From this it can be concluded that flowering of the parents under low irradiance, is a good indication for their breeding value for flowering under these conditions.

As the 5 varieties used in the experiments represent only a small sample of genotypes, some reservation should be made as to the assumption that this conclusion holds good for all HT varieties. Nevertheless in breeding for varieties that are adapted to winter light conditions, it seems advisable to hybridize parents that produce a high ratio of flowering to blind shoots.

Unfortunately in trials with new varieties of cut roses, the recording of blind 
shoots is omitted, so the above ratio cannot be calculated. For the breeder this means loss of vital information as the relative percentage of flowering of a variety is the best indication available for its breeding value for adaptation to low light intensity.

\section{References}

Garretsen, Frida \& M. Keuls, 1978. A general method for the analysis of genetic variation in complete and incomplete diallels and North Carolina II (NCII) designs. Part II. Procedures and general formulas for the fixed model. Euphytica 27: 49-68.

Keuls, M. \& Frida Garretsen, 1977. A general method for the analysis of genetic variation in complete and incomplete diallels and North Carolina II (NCII) designs. Part I. Procedures and general formulas for the random model. Euphytica 26: 537-551.

Vries, D. P. de, 1977. Shoot production in cut roses with reference to breeding for winter flowering. Euphytica 26: 85-88.

Vries, D. P. de \& L. Smeets, 1978. Hybrid Tea-roses under controlled light conditions. 2. Flowering of seedlings as dependent on the level of irradiance. Neth. J. agric. Cci. 26: 128132.

Vries, D. P. de, L. Smeets \& Lidwien A. M. Dubois, 1978. Hybrid Tea-roses under controlled light conditions. 3. Flower and blind shoot production in the glasshouse of seedlings selected for flowering or flower bud abortion at low irradiances in a growth room. Neth. J. agric. Sci. 26: 399-404. 